Original

\title{
Effects of Maternal Exposure to Nonylphenol on Growth and Development of the Female Reproductive System and Uterine Carcinogenesis in Rats
}

\author{
Midori Yoshida ${ }^{1}$, Takasumi Shimomoto ${ }^{1}$, Sayumi Katashima ${ }^{1}$, Tomoyuki Shirai², \\ Dai Nakae ${ }^{1}$, Gen Watanabe ${ }^{3}$, Kazuyoshi Taya ${ }^{3}$, and Akihiko Maekawa ${ }^{1}$ \\ ${ }^{1}$ Department of Pathology, Sasaki Institute, 2-2 Kanda-Surugadai, Chiyoda-ku, Tokyo 101-0062, Japan \\ ${ }^{2}$ Department of Experimental Pathology and Tumor Biology, Nagoya City University Graduate School of Medical \\ Sciences, Mizuho-ku, Nagoya, Japan \\ ${ }^{3}$ Veterinary Physiology, Tokyo University of Agriculture and Technology, Fuchu, Japan
}

\begin{abstract}
Effects of maternal exposure to nonylphenol (NP) on growth and development of the female reproductive system and uterine carcinogenesis in Donryu rats were investigated. Dams were administered 0, 0.1, $10 \mathrm{or} 100 \mathrm{mg} / \mathrm{kg}$ NP daily by gavage from gestation day 2 up to the day before weaning. The treatment with NP did not influence the reproductive ability of the dams. In their female offspring, there were no significant effects on the reproductive system such as uterine growth and development, vaginal opening, and hormonal secretion until puberty. Moreover, NP had no apparent influence on estrous cyclicity after maturation, morphology of the reproductive organs, and uterine carcinogenesis initiated by N-ethyl-N'-nitro-N-nitrosoguanidine. Regarding biotransfer of NP, the chemical was detected at low levels in the milk of dams given NP at 10 and $100 \mathrm{mg} / \mathrm{kg}$ /day in a dose-dependent manner, but not in the serum. In the offspring also, NP was not detected in the liver in any of the treated groups. Taken together, maternal exposure of rats to $0.1-100 \mathrm{mg} / \mathrm{kg} \mathrm{NP}$ did not have any effects on the female reproductive system of offspring from puberty up to 15 months of age. NP at $10 \mathrm{mg} / \mathrm{kg}$ and $100 \mathrm{mg} / \mathrm{kg}$ doses was transferred from dams to their offspring via the milk, but with these doses no accumulate in the liver of offspring was evident.
\end{abstract}

(J Toxicol Pathol 2003; 16: 259-266)

Key words: nonylphenol, endocrine disrupting chemicals, female reproductive system, maternal exposure

\section{Introduction}

Alkylphenolic compounds are derived from biodegradation of nonionic surfactants, alkylphenol ethoxylates, which are widely used as lubricating oil additives, plasticizers, resins, detergents, and surface-active agents. The nonylphenol group of ethoxylates is broken down into nonyphenol (NP), mainly found in rivers ${ }^{1}$. NP exerts weak estrogenic activity in vivo and in vitro ${ }^{2,3}$, binding to both estrogen receptors (ER) $\alpha$ and ER $\beta$ with low affinity ${ }^{4}$. Uterotropic effects of NP at high doses have been reported in immature or ovariectomized female rats ${ }^{2,5,6}$, as well as with octylphenol ${ }^{7-9}$.

The most serious issue with endocrine disrupting chemicals (EDCs) is potential effects of prenatal and/or neonatal exposure on offspring. Inappropriate exposure to

Received: 22 August 2003, Accepted: 24 October 2003

Mailing address: Midori Yoshida, Department of Pathology, Sasaki Institute, 2-2 Kanda-Surugadai, Chiyoda-ku, Tokyo 101-0062, Japan TEL: 81-3-3294-3286 FAX: 81-3-3294-3290

E-mail: midoriy@sasaki.or.jp endogenous and/or exogenous estrogens is known to induce irreversible change in the reproductive system, with an influence on uterine carcinogenesis ${ }^{10-15}$. However, the perinatal effects of EDCs on the reproductive organs in rodents are very complex and the underlying mechanisms remain to be determined in detail. In reproductive toxicity studies, high-dose NP exposure resulted in estrogeniceffects on pubertal development in male and female rats ${ }^{16-18}$. However, relatively low dose maternal or perinatal exposure to NP demonstrated no adverse effects on the reproductive tract in rodents ${ }^{17}$, although perinatal treatment with estrogenic EDCs at doses comparable to human exposure levels has been reported to exert an influence ${ }^{19-22}$. For human risk assessment, it is very important to determine the effects of actual exposure to EDCs on reproductive organs, but the studies so far conducted in accordance to the test guidelines for safety evaluation did not demonstrate adverse effects or the results were controversial. One reason for the latter is the lack of established endpoint markers to detect maternal or perinatal effects of EDCs in rodents, especially females. It has been reported that a 'delayed' influence of EDCs on the reproductive system of rodents exposed 
perinatally may be manifested after puberty or sexual maturation ${ }^{15,23,24}$. Thus, relatively long-term comprehensive studies of endocrinological and morphological aspects might be necessary for determination of the impact of perinatal treatment with EDCs. At the same time, with maternal exposure it is crucial to examine biotransfer of chemicals from dams to offspring, because the effects of EDCs on the target organs are fundamentally related to serum levels ${ }^{8}$. Little information is available regarding test compound transfer from dams to offspring via the placenta or milk.

The purpose of the present study was to investigate the effects of maternal exposure to NP at low to high exposuredoses, with reference to growth and development of the female reproductive tract and also uterine carcinogenesis in rats. For these purposes a relatively long-term period from prepuberty up to 15 months of age was employed with many parameters to detect effects of EDCs reported previously. In addition, we assessed transfer of NP to offspring via the placenta and milk.

\section{Materials and Methods}

\section{Animals, NP treatment, and housing conditions}

Thirty seven pregnant female Crj:Donryu rats at gestation day (GD) 2, checked by plugs and sperm in the vagina and judged to be pregnant by the breeder, were purchased from Charles River Japan (Kanagawa, Japan) and allocated into four groups: $0 \mathrm{mg} / \mathrm{kg} /$ day (vehicle controls, 10 dams), $0.1 \mathrm{mg} / \mathrm{kg} /$ day NP (Tokyo Kasei Kagaku, Tokyo, Japan, 10 dams), $10 \mathrm{mg} / \mathrm{kg} /$ day NP (10 dams), and $100 \mathrm{mg} /$ $\mathrm{kg}$ /day NP (7 dams). The highest dose is known to have adverse effects, with uterotropic- and cell-proliferative activity observed in the uterus and mammary glands in rats when given by gavage ${ }^{25}$. The middle-dose was selected as near the no observed effect level in multiple generation reproductive study using rats $^{16}$ and the lowest dose as relevant to human daily intake of isoflavones in Germany ( $1 \mathrm{mg} / \mathrm{kg}$ ), because uterotrpopic activity of NP was reported to be 10 times stronger than that of daidzein, a major isoflavone ${ }^{26}$. NP was suspended in $0.05 \%$ carboxymethylcellulose (CMS) solution (Wako Pure Chemicals, Osaka, Japan) for this purpose. The females were orally administered NP or vehicle solution $(0.05 \%$ CMC), every morning from GD 2 to the day before weaning (21 days after delivery) by gavage. The treatment period was selected to observe effects of maternal exposure to NP as long as possible. Commercial pellet diet (CRF-1, Oriental Yeast, Co., Japan) and drinking water stored in plastic containers were available ad libitum throughout the study. The day of birth was designated postnatal day (PND) 0 . After delivery, dams with offspring were housed in plastic cages containing wooden chips, and litter sizes were adjusted to $8-10$ pups/dam at PNDs 4 or 6 . All pups were weaned at PND 21 and female pups in the same treatment group were housed together in cages ( 3 or 4 pups per cage). Animals were maintained in air-conditioned animal rooms under constant conditions of $24 \pm 2{ }^{\circ} \mathrm{C}$ and $55 \pm 10 \%$ humidity with a 12-h light/dark cycle. Animal care and use followed the NIH Guide for the Care and Use of Laboratory Animals.

\section{Examination of dams}

Body weights of dams were checked once a week during the pregnancy and lactating periods. All dams were observed at least twice a day for morbidity, mortality and treatment-related clinical signs. Dams were euthanized at weaning (PND21 of their offspring) and the numbers of implantation sites in the uterus were recorded after complete necropsy. The uterus, vagina, ovaries, pituitary, adrenals, liver, and kidneys were fixed in $10 \%$ neutral buffered formaldehyde solution and examined histopathologically.

\section{Examination of offspring}

Body weights, sex, the number of offspring and external abnormalities were checked at PNDs 1, 7, 14 and 21.

Uterine growth and development at prepuberty and ovulation: To investigate uterine growth and development of female offspring up to puberty, 3 or 4 animals per group being different littermate were euthanized by decapitation at PNDs 10, 14, 21, and 28, the individual animals at each timepoint being derived from different dams. After the uteri were weighed, the numbers of uterine glands were histopathologically quantified. Briefly, the uteri were fixed in $10 \%$ neutral buffered formalin solution, 21 cross sections per uterine horn were taken from upper, middle and lower parts of the bilateral uterine horn, and examined histopathologically. To assess ER $\alpha$ expression and cell proliferative activity in the developing uteri, serial uterine sections from slices used for measurement of uterine glandgenesis were incubated with anti-ER $\alpha$ and anti-proliferating cell nuclear antigen antibodies (Dako, Kyoto, Japan), for immunohistochemical comparison with control animals. In the morning of the estrus stage at 8 weeks of age, 4 animals per each group were euthanized and the numbers of ova in the oviduct were counted. The ovaries, vagina and other representative organs were fixed in $10 \%$ neutral buffered formaldehyde solution at PNDs 10, 14, 21, and 28 and 8 weeks of age and processed routinely for histopathological examination.

Hormonal profiles at prepuberty: Blood from the same animals used for histopathological examination was collected after decapitation and serum was stored at $-80^{\circ} \mathrm{C}$ until assayed. Up to PND 14, pooled serum samples were used, since volume of serum per single animal was too small to allow analysis. Serum follicle stimulating hormone (FSH) and inhibin (INH) levels at PNDs 10, 14, 21, or 28 were measured using NIDDK radioimmunoassay kits for rat $\mathrm{FSH}^{27-29}$.

Vaginal opening and estrous cyclicity: After weaning, female pups were checked daily for vaginal opening. After this was confirmed, estrous cyclicity in all animals was examined by vaginal cytology throughout the study.

Uterine carcinogenicity study: All female pups at 11 
Table 1. Reproductive Ability and Body Weights of Offspring

\begin{tabular}{|c|c|c|c|c|}
\hline & \multicolumn{4}{|c|}{ Group } \\
\hline & $0 \mathrm{mg} / \mathrm{kg}$ & $0.1 \mathrm{mg} / \mathrm{kg}$ & $10 \mathrm{mg} / \mathrm{kg}$ & $100 \mathrm{mg} / \mathrm{kg}$ \\
\hline No. of dams & 10 & 10 & 10 & 7 \\
\hline Pregnant & 10 & 10 & 10 & 7 \\
\hline At the termination of PND21 & 10 & 10 & 10 & 7 \\
\hline Pregnant period & $21 \pm 0.0(\#)$ & $21.11 \pm 0.33$ & $21 \pm 0.0$ & $21 \pm 0.0$ \\
\hline \multicolumn{5}{|l|}{ No. of pups at birth (g) } \\
\hline Female & $5.6 \pm 1.84$ & $6.5 \pm 1.84$ & $6.3 \pm 1.06$ & $5.2 \pm 2.66$ \\
\hline Male & $5.5 \pm 1.96$ & $5.9 \pm 2.64$ & $6.8 \pm 1.75$ & $6.5 \pm 2.42$ \\
\hline Total (a) & $11.1 \pm 2.13$ & $12.4 \pm 1.71$ & $13.1 \pm 1.20$ & $12.0 \pm 2.71$ \\
\hline \multicolumn{5}{|c|}{ No. of dead pups during PNDs $1-5$} \\
\hline Female & $0 \pm 0.00$ & $0 \pm 0.00$ & $0 \pm 0.00$ & $0 \pm 0.00$ \\
\hline Male & $0 \pm 0.00$ & $0 \pm 0.00$ & $0.7 \pm 1.89$ & $0.3 \pm 1.41$ \\
\hline No. of implantation (b) & $12.5 \pm 1.35$ & $13 \pm 1.41$ & $13.9 \pm 0.99$ & $13.0 \pm 1.63$ \\
\hline $\mathrm{a} / \mathrm{b}$ & $0.89 \pm 0.15$ & $0.95 \pm 0.09$ & $0.94 \pm 0.07$ & $0.9 \pm 0.17$ \\
\hline
\end{tabular}

$\mathrm{A} \pm \mathrm{B}(\#)$, Mean \pm SD. PNDs, post natal days.

weeks of age were administered a single dose of $20 \mathrm{mg} / \mathrm{kg}$ $\mathrm{N}$-ethyl-N'-nitro-N-nitrosoguanidine (ENNG, Nacarai Tesque Inc., Tokyo Japan) into a uterine horn using a stainless steel catheter via the vagina, as reported previously ${ }^{30}$. At 12 months of age, 5 or 6 animals per group were euthanized and examined histologically to evaluate development of uterine proliferative lesions. At the termination (15 months of age), all surviving animals underwent a histopathological examination. After complete necropsy, the reproductive and representative organs were fixed in $10 \%$ neutral buffered formalin, and then routinely processed. Animals found dead and killed when moribund were also examined similarly. Each uterus was cut into about 12-16 slices in cross-section for hematoxylin and eosin staining. Endometrial proliferative lesions were classified into three degrees of hyperplasia (slight, moderate or severe) and adenocarcinomas, according to our categories described previously ${ }^{31}$. In addition, adenocarcinomas were subdivided into well, moderately and poorly differentiated types, and also classified as to the degree of invasion: limited to the uterus, invading into the serosa and/or surrounding adnexae and tumors with distant metastasis, in accordance with the simplified FIGO histopathological grades for human uterine cancers ${ }^{32}$.

Serum and tissue concentration of NP in dams and their offspring

Serum and milk of dams were collected at weaning from offspring and at PNDs 10, respectively. The milk in the stomachs of the male and female pups was collected and pooled for each litter. In offspring, NP levels in the liver were sequentially measured at PNDs 21 and 28 . The analysis was accomplished by gas chromatography mass spectrometry (QT-5050, Shimadzu, Kyoto, Japan) using the modified method reported previously ${ }^{8}$.

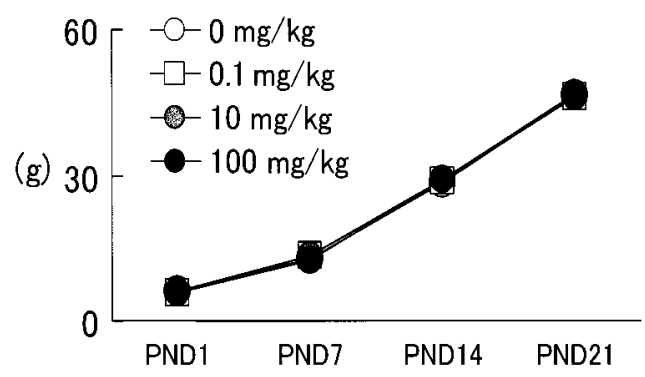

Fig. 1. Growth curve of female offspring up to the weaning. The body weights are comparable among the groups.

\section{Statistical analysis}

Values for incidences were statistically analyzed using the Fisher's exact probability test. Other data were analyzed using ANOVA, and post hoc comparisons between NPtreated and control groups were made with the Dunnett's ttest. p Values less than 0.05 were considered to be statistically significant.

\section{Results}

The body weights of dams were comparable in the control and treated groups during the NP-treatment period (GD2 to PND21) and no treatment-related clinical signs were observed in any treated groups. Table 1 shows data of reproductive ability of dams. Examinations at birth and necropsy revealed no significant differences among the groups in the gestation period, the number of implantation sites, the average number of offspring per litter, and the body weights of offspring.

In female offspring, the growth curves were comparable among control and treated groups from prepuberty (Fig. 1) up to 15 months of age and no external abnormalities were detected in any offspring. Data of 


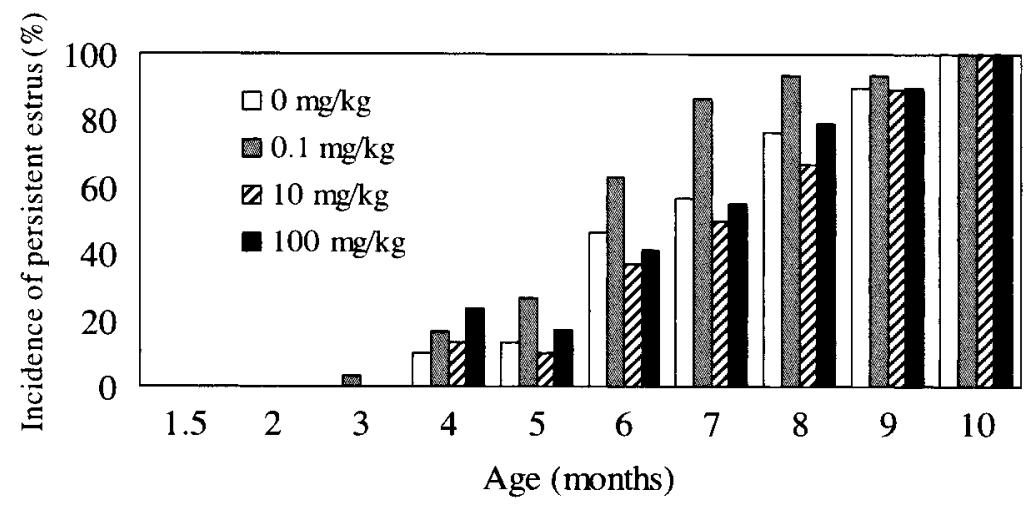

Fig. 2. The incidence (\%) of animals showed persistent estrus (PE) at their vaginal cytology. The number of the animals with $\mathrm{PE}$ is increased with advanced age and their incidence is not significantly different among the groups.

Table 2. Growth and Development of the Female Reproductive Organs in Offspring

\begin{tabular}{|c|c|c|c|c|}
\hline \multirow[t]{2}{*}{ Time of examined } & \multicolumn{4}{|c|}{ Group } \\
\hline & $0 \mathrm{mg} / \mathrm{kg}$ & $0.1 \mathrm{mg} / \mathrm{kg}$ & $10 \mathrm{mg} / \mathrm{kg}$ & $100 \mathrm{mg} / \mathrm{kg}$ \\
\hline \multicolumn{5}{|c|}{ Number of rats examined } \\
\hline PNDs10 & 4 & 3 & 4 & 2 \\
\hline PNDs14 & 4 & 3 & 4 & 3 \\
\hline PNDs21 & 4 & 4 & 4 & 4 \\
\hline PNDs28 & 4 & 4 & 4 & 4 \\
\hline 17 wks* & 4 & 4 & 4 & 4 \\
\hline \multicolumn{5}{|l|}{ Uterine weights (mg) } \\
\hline PNDs14 & $26.8 \pm 6.0$ & $28.3 \pm 5.0$ & $32.3 \pm 4.3$ & $21.0 \pm 1.0$ \\
\hline PNDs21 & $42.3 \pm 5.6$ & $41.0 \pm 7.2$ & $38.3 \pm 7.7$ & $46.3 \pm 3.8$ \\
\hline PNDs28 & $141.6 \pm 34.2$ & $187.3 \pm 137.4$ & $242.3 \pm 145.2$ & $290.8 \pm 134.6$ \\
\hline 17 wks & $712.3 \pm 117.7$ & $653.3 \pm 76.8$ & $653.3 \pm 76.8$ & $720.8 \pm 113.1$ \\
\hline \multicolumn{5}{|c|}{ Uterine gland-genesis (Number of gland per cross section) } \\
\hline PNDs10 & 0 & 0 & 0 & 0 \\
\hline PNDs14 & $4.07 \pm 1.49$ & $4.27 \pm 1.74$ & $4.29 \pm 1.59$ & $3.00 \pm 0.87$ \\
\hline PNDs21 & $4.57 \pm 1.60$ & $4.76 \pm 1.15$ & $5.31 \pm 1.49$ & $4.78 \pm 2.46$ \\
\hline PNDs28 & $6.00 \pm 2.62$ & $5.92 \pm 1.26$ & $5.73 \pm 2.34$ & $5.07 \pm 1.77$ \\
\hline \multicolumn{5}{|c|}{ The time of vaginal opening (days) } \\
\hline & $29.6 \pm 1.8$ & $30.1 \pm 1.3$ & $29.8 \pm 1.1$ & $29.0 \pm 1.4$ \\
\hline \multicolumn{5}{|c|}{ Number of rats examined } \\
\hline & 34 & 34 & 34 & 34 \\
\hline \multicolumn{5}{|c|}{ Ovulation (Number of ova in the oviduct in the morning of estrus at 17 wks of age) } \\
\hline & $11.3 \pm 1.5$ & $11.3 \pm 1.5$ & $11.5 \pm 1.0$ & $12.3 \pm 0.6$ \\
\hline
\end{tabular}

*; Examined in the morning at estrus stage.

females are shown in Table 2; the days of vaginal opening of offspring demonstrated no significant intergroup differences. Thereafter, precise 4-day cycles of estrous stages started in all animals. Persistent estrus, characterized by vaginal smears exhibiting nucleated epithelial and/or cornified cells, began to appear after 5 months of age in control animals and gradually increased with age in this group, all animals showing persistent estrus at 10 months of age, as shown in Fig. 2. In all NP-treated groups also, occurrence of persistent estrus demonstrated a similar profile. At PNDs 14, 21, 28, and 8 weeks of age, uterine weights did not differ among the groups, and sequential changes in number of uterine glands in both treated and control animals were comparable (Table 2). No obvious changes in morphology, expression of estrogen receptor $\alpha$ or proliferative activity in the uterus were observed in any of the treated groups before puberty, compared to those in controls. Other endocrine tissues and representative organs showed no abnormalities in NP-treated and control groups. The numbers of ova at 8 weeks of age were not significantly different among the groups (Table 2).

Serum FSH and inhibin levels for NP-treated and 

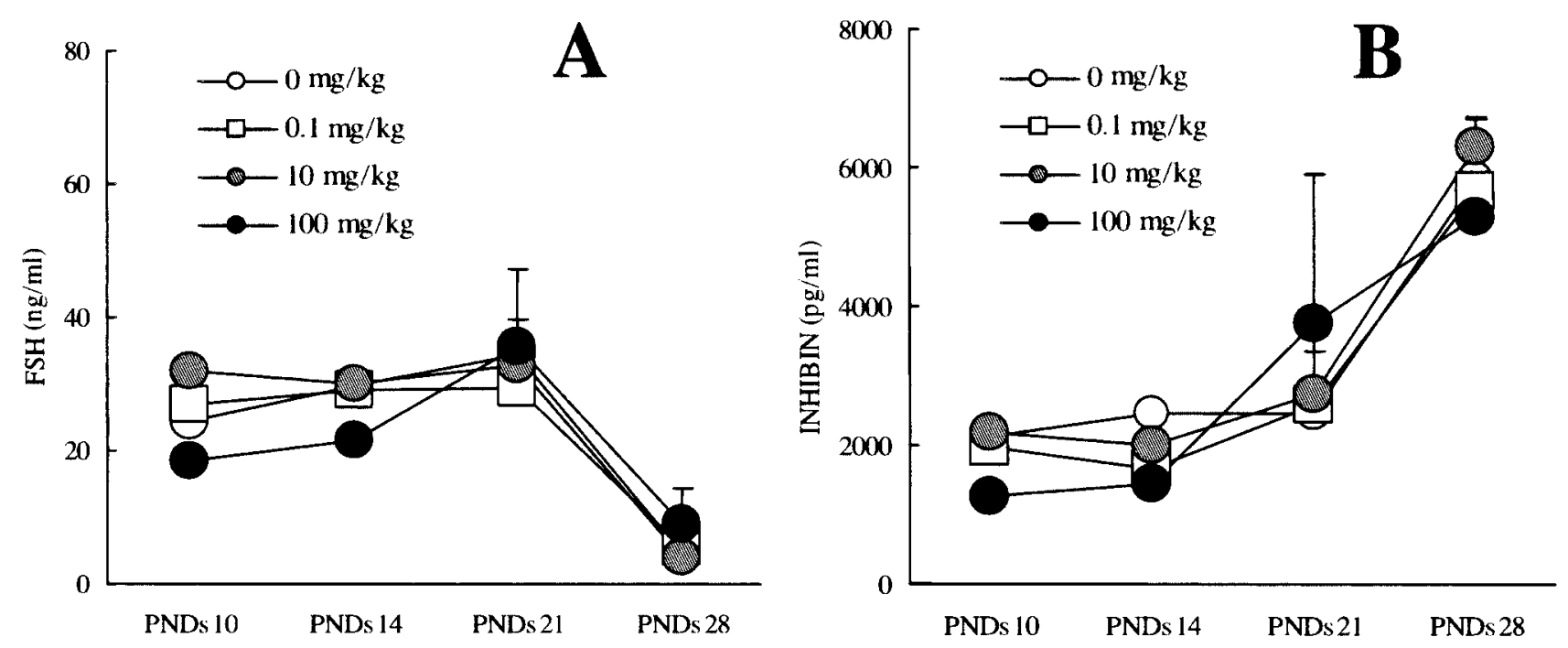

Fig. 3. Serum hormone profiles of follicle stimulating hormone, gonadotropin (A), and inhibin, a hormone secreted in the ovary (B) up to puberty. In all treated groups, FSH levels are comparable to that in controls. Inhibin levels were anti-related with levels of FSH.

Table 3. Incidence of Uterine Proliferative Lesions

\begin{tabular}{rcccccc}
\hline & & & \multicolumn{3}{c}{ No. of rats with lesions } \\
\cline { 4 - 5 } Group & No. of rats & $\begin{array}{c}\text { No. of rats } \\
\text { examined }\end{array}$ & \multicolumn{3}{c}{ Hyperplasia } & Adenocarcinoma \\
\cline { 4 - 5 } & without lesions & Slight & Moderate & Severe & \\
\hline $0 \mathrm{mg} / \mathrm{kg}$ & 24 & $3(13)^{*}$ & $3(13)$ & $8(33)$ & $4(17)$ & $6(25)$ \\
$0.1 \mathrm{mg} / \mathrm{kg}$ & 24 & $2(8)$ & $3(13)$ & $9(38)$ & $1(4)$ & $9(38)$ \\
$10 \mathrm{mg} / \mathrm{kg}$ & 23 & $1(4)$ & $1(4)$ & $10(43)$ & $3(13)$ & $8(35)$ \\
$100 \mathrm{mg} / \mathrm{kg}$ & 22 & $1(5)$ & $2(9)$ & $5(23)$ & $4(18)$ & $10(45)$ \\
\hline
\end{tabular}

*( ); Percentage.

control rats at prepuberty are shown in Fig. 3. Up to PND 28, serum FSH and its linked inhibin levels were comparable among NP-treated and control groups, and the gonadotropins demonstrated no tendency for lowering with the treatment.

The incidences of uterine preneoplastic and neoplastic lesions are shown in Table 3. There were no significant differences and/or treatment-related tendencies among the groups. Sub-classification of adenocarcinomas by differentiation and invasion also demonstrated no variation. Most of the ovaries in all groups were atrophic with small cystic follicles and lacking corpus lutea. Various nonneoplastic and neoplastic lesions were observed in the representative organs and other endocrine tissues such as the liver, kidneys, adrenals, pituitary, and thyroids in all groups, although there were no significant differences among the NP-treated and control groups. Necropsy of animals found dead or euthanized when moribund did not reveal any treatment-related changes.

Serum and tissue concentrations of NP are summarized in Table 4. In dams, NP was detected in milk at PND 14 with dose dependence in the 10 and $100 \mathrm{mg} / \mathrm{kg}$ groups, but not serum. NP was not found to have accumulated in the livers of offspring in any of the treated groups at PNDs 21 and 28, the latter being 7 days after the final treatment.

\section{Discussion}

Inappropriate exposure to estrogens or EDCs with estrogenic activity in the fetal and/or newborn period is well known to exert irreversible influence on the female reproductive system due to disruption of the hypothalamicpituitary-ovary controlled system. Typically 'androgenized' influences appear in prepuberty, characterized by lowering of gonadotropin levels, anovulation, hypoplastic ovary, persistent estrus status immediately after early vaginal opening, and abnormal uterine development, with inhibition of gland-genesis and anomalous ER $\alpha$ expression ${ }^{10,14,15,33}$. In addition to the typical 'androgenized' effects described above, perinatal exposure may also cause 'delayed' effects including the 'anovulatory syndrome'15,23,24. For example, high-dose exposure to $p$-tert-octylphenol, an alkylphenolic compound with weak estrogenic activity, during the first 5 days after birth in female Donryu rats exerted a delayed influence, detected as ovarian atrophy with polycystic 
Table 4. Tissue and Serum Concentration of Nonylphenol

\begin{tabular}{lcccc}
\hline & \multicolumn{4}{c}{ Group } \\
\cline { 2 - 5 } & $0 \mathrm{mg} / \mathrm{kg}$ & $0.1 \mathrm{mg} / \mathrm{kg}$ & $10 \mathrm{mg} / \mathrm{kg}$ & $100 \mathrm{mg} / \mathrm{kg}$ \\
\hline Dam & & & & \\
Serum level at PNDs21 & $<0.1 \mathrm{ppm} *$ & $<0.1 \mathrm{ppm}$ & $<0.1 \mathrm{ppm}$ & $<0.1 \mathrm{ppm}$ \\
Number of dam pooled & 5 & 5 & 5 & 5 \\
Milk at PNDs14 & $<0.1 \mathrm{ppm}$ & $<0.1 \mathrm{ppm}$ & $0.4 \mathrm{ppm}$ & $1.6 \mathrm{ppm}$ \\
Number of pup stomach collected & 8 & 8 & 8 & 6 \\
Offspring & & & & \\
Liver at PNDs21 & $<0.1 \mathrm{ppm}$ & $<0.1 \mathrm{ppm}$ & $<0.1 \mathrm{ppm}$ & $<0.1 \mathrm{ppm}$ \\
Number of pup pooled & 4 & 4 & 4 & 6 \\
Liver at PNDs28 & $<0.1 \mathrm{ppm}$ & $<0.1 \mathrm{ppm}$ & $<0.1 \mathrm{ppm}$ & $<0.1 \mathrm{ppm}$ \\
Number of pup pooled & 4 & 4 & 4 & 4 \\
\hline
\end{tabular}

*; Under the detectable limit.

Table 5. Comparison of Effects on the Female Reproductive System in the Present Study with Previous Studies Showing Typical Androgenized- or Delayed Androgenized-effects

\begin{tabular}{|c|c|c|c|c|c|}
\hline & \multicolumn{3}{|c|}{ Nonyphenol by gavage (present study) } & \multicolumn{2}{|c|}{ Octhylphsenol (previous studies) } \\
\hline & $0.1 \mathrm{mg} / \mathrm{kg}$ & $10 \mathrm{mg} / \mathrm{kg}$ & $100 \mathrm{mg} / \mathrm{kg}$ & $\begin{array}{l}\text { Typical androgenization (a) } \\
100 \mathrm{mg} / \mathrm{kg} \text { subcutanrous }\end{array}$ & $\begin{array}{c}\text { Delayed-androgenization (b) } \\
100 \mathrm{mg} / \mathrm{kg} \text { subcutaneous }\end{array}$ \\
\hline \multicolumn{6}{|l|}{ Examinations at prepuberty } \\
\hline Growth & $\mathrm{N}(\mathrm{c})$ & $\mathrm{N}$ & $\mathrm{N}$ & $\mathrm{N}$ & $\mathrm{N}$ \\
\hline Uterine weight & $\mathrm{N}$ & $\mathrm{N}$ & $\mathrm{N}$ & $\mathrm{N}$ & $\mathrm{N}$ \\
\hline Uterine gland-genesis & $\mathrm{N}$ & $\mathrm{N}$ & $\mathrm{N}$ & $\downarrow(d)$ & $\mathrm{N}$ \\
\hline $\begin{array}{l}\text { Expression of estrogen re } \\
\text { in the uteri }\end{array}$ & $\mathrm{N}$ & $\mathrm{N}$ & $\mathrm{N}$ & Abnormal & $\mathrm{N}$ \\
\hline Time of vaginal opening & $\mathrm{N}$ & $\mathrm{N}$ & $\mathrm{N}$ & Early opening & $\mathrm{N}$ \\
\hline Gonadtoropin secretion & $\mathrm{N}$ & $\mathrm{N}$ & $\mathrm{N}$ & $\downarrow$ & $\mathrm{N}$ \\
\hline \multicolumn{6}{|c|}{ Examinations after maturation } \\
\hline Ovulation & $\mathrm{N}$ & $\mathrm{N}$ & $\mathrm{N}$ & Anovulation & $\mathrm{N}$ \\
\hline Estrous cyclicity & $\mathrm{N}$ & $\mathrm{N}$ & $\mathrm{N}$ & PE (e) & $\begin{array}{l}\text { Normal after vaginal opening } \\
\text { but earlier occurrence of PE }\end{array}$ \\
\hline Uterine carcinogenesis & $\mathrm{N}$ & $\mathrm{N}$ & $\mathrm{N}$ & Enhanced & Enhanced \\
\hline
\end{tabular}

(a); Exposure of octylphenol during first 15 days after the birth referred by Katsuda et al., 2000A(14) and Yoshida et al., 2002A(33).

(b); Exposure of octylphenol during first 5 days after the birth Referred by Yoshida et al., 2002B(15).

(c); Normal or comparable data compared with those in the control animals.

(d); Decreased.

(e); PE, Persistent estrus at vaginal cytology.

follicles resulting in early persistent estrus compared to aged-matched control animals, although no apparent abnormalities were found up to maturation ${ }^{15}$. In the present study, however, NP-treated animals showed no abnormalities in gonadotropin and associated ovarian hormone secretion, or in uterine growth and development. Thus uterine gland-genesis and ER $\alpha$ expression as well as the time of vaginal opening and subsequent sexual maturation were comparable to those in controls. The treatment also did not exert any effects on ovulation and estrous cyclicity throughout the study, as compared to the age-matched control animals or our control data for the Donryu strain rat. The results clearly demonstrated that maternal treatment with $0.1-100 \mathrm{mg} / \mathrm{kg}$ NP did not exert any influence on the female reproductive system of offspring at prepuberty, and delayed modulation of the system after sexual maturation appeared lacking.

The most striking examples of the effects caused by EDCs on the female reproductive system are induction of vaginal or uterine cancers in humans and rodents ${ }^{34-36}$. Recently many studies of induction of uterine endometrial adenocarcinomas in rodents by perinatal treatment with estrogenic compounds or EDCs have been conducted $^{12,15,35,37}$. The uterine endometrial adenocarcinoma is one of the most common malignant tumors in women and has increased in number in recent years, although some epidemiological aspects remain unclear ${ }^{38,39}$. The Donryu strain rat is a high-incidence strain for spontaneous endometrial adenocarcinomas and the tumors have morphological and biological similarities to those found in 
women ${ }^{40-42}$. Similar to the human case, ovarian hormonal imbalance is a crucial factor. In particular, the model features early occurrence of ovarian atrophy with cystic atresia follicles and lack of corpus lutea, associated with prolonged elevation of the serum estrogen/progesterone ratio and persistent estrus in vaginal cytology ${ }^{43}$. In the present study, maternal treatment of NP did not exert any influence on estrous cyclicity and uterine carcinogenesis. To determine ovarian function in rats, examination of estrous cyclicity might be the most useful indicator, as previously reported $^{44}$.

For assessment of effects of EDCs on offspring with maternal treatment, biotransfer from dams is crucial because the effects on the target organs are fundamentally related to serum EDCs levels ${ }^{8}$. However, data for transfer of test compound via the placenta or milk to offspring and toxicokinetics of low-dose EDCs were very limited ${ }^{45}$. In the present study, NP levels in the milk of the 10 and $100 \mathrm{mg} / \mathrm{kg}$ groups were elevated, but the compound was not detected in the serum of dams and the liver of offspring.

A summary of the present study results in comparison with androgenized- or delayed androgenized-effects reported previously is given in Table 5. We can conclude that transplacental and lactational exposure to various doses NP does not appreciably influence the growth and development of the female reproductive system or sensitivity to uterine carcinogenesis. No accumulation of the compound was found in the offspring livers, although NP was detectable in the milk at 10 and $100 \mathrm{mg} / \mathrm{kg}$.

Acknowledgements: This study was supported by a GrantAid from the Ministry of Health, Labor and Welfare of Japan. We sincerely appreciate the expert animal technical assistance of Mr. K Ohara and Mr. K Ochiai, and excellent histopathological technique of Ms. Ichihara, H. and Ms. Asako H.

\section{References}

1. Purdom CE, Hardiman PA, Bye VJ, Eno NC, Tyler CR, and Sumpter JP. Estrogenic effects of effluents from sewage treatment works. Chem Ecol 1994; 8: 275-285.

2. Soto AM, Justicia H, Wray JW, and Sonnenshein C. pNonyl-phenol: An estrogenic xenobiotic released from "modified" polystyrene. Environ Health Perspect 1991; 92: $167-173$

3. White R, Jobling S, Hoare A, Sumpter JP, and Parker MG. Environmental persistent alkylphenolic compounds are estrogenic. Endocrinol 1994; 135: 175-182.

4. Kuiper GG, Lemmen JG, Carlsson B, Corton JC, Safe SH, van der Saag PT, van der Burg B, and Gustafsson JA. Interaction of estrogenic chemicals and phytoestrogens with estrogen receptor beta. Endocrinol 1998; 139: 4252-4263.

5. Law SC, Carey SA, Ferrell JM, Bodman GJ, and Cooper RL. Estrogenic activity of octylphenol, nonylphenol, bisphenol A and methoxychlor in rats. Toxicol Sci 2000; 54: 156-167.

6. Odum J, Pyrah ITG, Soames AR, Foster JR, Vanmiller JP, Joiner RL, and Ashby J. Effects of p-nonylphenol (NP) and diethylstilbestrol (DES) on the Alderley park (Alpk) rat: comparison of mammary gland and uterus sensitivity following oral gavage or implanted mini-pumps. J Appl Toxicol 1999; 19: 367-378.

7. Blake CA and Ashiru OA. Disruption of rat estrous cyclicity by the environmental estrogen 4-tert-octylphenol. Proc Soc Exp Biol Sci 1997; 216: 446-451.

8. Katsuda S, Yoshida M, Isagawa S, Asagawa Y, Kuroda H, Watanabe T, Ando J, Takahashi M, and Maekawa A. Doseand treatment duration-dependent effects of p-tertoctylphenol on female rats. Reprod Toxicol 2000A; 14: 119126.

9. Yoshida M, Katsuda S, Ando J, Kuroda H, Takahashi M, and Maekawa A. Subcutaneous treatment of p-tertoctylphenol exerts estrogenic activity on the female reproductive tract in normal cycling rats of two different strains. Toxicol Lett 2000; 116: 89-101.

10. Branham WS, Sheeman DM, Zehr DR, Ridlon E, and Nelson CJ. The postnatal ontogeny of rat uterine glands and age-related effects of $17 \beta$-estradiol. Endocrinol 1985; 117: 2229-2237.

11. Cheng HC and Johnson DC. Serum estrogens and gonadotropins in developing androgenized and normal female rats. Neuroendocrinol 1974; 13: 357-365.

12. Kitamura T, Nishimura S, Sasahara K, Yoshida M, Ando J, Takahashi M, Shirai T, and Maekawa A. Transplacental administration of diethylstilbetrol (DES) causes lesions in female reproductive organs of Donryu rats, including endometrial neoplasia. Cancer Lett 1999; 141: 219-228.

13. Takasugi N, Bern HA, and DeOme KB. Persistent vaginal cornification in mice. Science 1962; 138: 438-439.

14. Katsuda S, Yoshida M, Watanabe G, Taya K, and Maekawa A. Irreversible effects on the reproductive tract of female rats by neonatal exposure to p-tert-octylphenol. Toxicol Appl Pharmacol 2000B; 165: 217-226.

15. Yoshida M, Katsuda S, Tanimoto T, Asai S, Nakae D, Kurokawa Y, Taya K, and Maekawa A. Induction of different types of uterine adenocarcinomas in Donryu rats due to neonatal exposure to high-dose p-t-octylphenol for different periods. Carcinogenesis 2002B; 23: 1745-1750.

16. Chapin RE, Delaney J, Wang Y, Lanning L, Davis B, Collins B, Minz N, and Wolfe G. The effects of 4nonylphenol in rats: A multi-generation reproduction study. Toxicol Sci 1999; 52: 80-91.

17. Nagano T, Wada K, Marumo H, Yoshimura S, and Ono H. Reproductive effects of nonylphenol in rats after gavage administration: a two-generation study. Reprod Toxicol 2001; 15: 293-315.

18. NTP Final Report on the reproductive toxicity of nonylphenol (CAS \#84852-15-3) administered by gavage to Sprague-Dawley rats. NTP Report \#RACB 94021. 1997.

19. Fisher JS, Turner KJ, Brown D, and Sharpe RM. Effect of neonatal exposure to estrogenic compounds on development of the excurrent ducts of the rat testis through puberty to adulthood. Environ Health Perspect 1999; 107: 397-405.

20. Nagel SC, vom Saal FS, Thayer KA, Dhar MG, Boechler M, and Welshons WV. Relative binding affinity-serum modified access (RBA-SMA) assay predicts the relative in vivo bioactivity of the xenoestrogens bisphenol $\mathrm{A}$ and octylphenol. Environ Health Perspect 1997; 105: 70-76.

21. Sharpe RM, Fisher J, Milar MR, Jobling S, and Sumpter JS. Gestational and/or neonatal exposure of rats to 
environmental estrogenic chemicals results in reduced testis size and daily sperm production in adulthood. Environ Health Perspect 1995; 103: 1136-1143.

22. vom Saal FS, Cooke PS, Buchanan DL, Palanza P, Thayer KA, Nagel SC, Parmigiani S, and Welshons WV. A physiologically based approach to the study of bisphenol A and other estrogenic chemicals on the size of reproductive organs, daily sperm production, and behavior. Toxicol Ind Health 1998; 14: 239-260.

23. Herath CB, Watanabe G, Katsuda S, Yoshida M, Suzuki A, and Taya K. Exposure to neonatal female rats to p-tertoctylphenol disrupts afternoon surges of luteinizing hormone, follicle-stimulating hormone, and prolactin secretion, and interferes with sexual receptive behavior in adulthood. Biol Reprod 2001; 64: 1216-1224.

24. MacLusky NJ and Naftolin F. Sexual differentiation of the central nervous system. Science 1981; 211: 1294-1303.

25. Odum J, Lefervre PA, Tittensor S, Paton D, Routledge EJ, Bereford NA, Sumper JP, and Ashby J. The rodent uterotropic assay: Critical protocol features, studies with nonylphenols, and comparison with a yeast estrogenicity assay. Regul Toxicol Pharmacol 1997; 25: 176-188.

26. Bolt HM, Schuhmacher US, and Degen GH. Special aspects of endocrine modulators in human and environmental risk assessment of existing chemicals. Arch Toxicol 1998; 72: A72-A75.

27. Noguchi J, Hikono H, Sato S, Watanabe G, Taya K, and Sasamoto S. Ontogeny of inhibin secretion in the rat testis: secretion of inhibin-related proteins from fetal Leydig cells and of bioactive inhibin from Sertoli cells. J Endocrinol 1997; 155: 27-34.

28. Taya $\mathrm{K}$ and Sasamoto S. Age-related changes in the secretory pattern of FSH and LH in response to LH-RH in prepubertal female rats. Endocrinol Jpn 1988; 35: 349-355.

29. Watanabe G, Taya K, and Sasamoto S. Dynamics of ovarian inhibin secretion during the oestrous cycle in the rat. J Endocrinol 1990; 126: 151-157.

30. Ando-Lu J, Takahashi M, Imai S, Ishihara R, Kitamura T, Iijima T, Takano S, Nishiyama K, Suzuki K, and Maekawa A. High-yield induction of endometrial adenocarcinomas in Donryu rats by a single intra-uterine administration of $\mathrm{N}$ ethyl-N'-nitro-N-nitrosoguanidine. Jpn J Cancer Res 1994; 85: 789-793.

31. Nagaoka T, Takeuchi M, Onodera H, Matsushima Y, AndoLu J, and Maekawa A. Sequential observation of spontaneous endometrial adenocarcinoma development in Donryu rats. Toxicol Pathol 1994; 22: 261-269.

32. Pecorelli S, Benedet JL, Creasman WT, and Shepherd JH. FIGO staging of gynecologic cancer. Int J Gynecol Obstet
1999; 64: 5-10.

33. Yoshida M, Takenaka A, Katsuda S, Kurokawa Y, and Maekawa A. Neonatal exposure to p-tert-octylphenol causes abnormal expression of estrogen receptor $\alpha$ and subsequent alteration of cell-proliferating activity in the developing Donryu rat uterus. Toxicol Pathol 2002A; 30: 357-364.

34. Herbst AL, Ulfelder H, and Poskanzer DC. Adenocarcinoma of the vagina. Association of maternal stilbestrol therapy with tumor appearance in young women. New Engl J Med 1971; 184: 878-881.

35. Newbold RR, Bullock BC, and McLachlan JA. Uterine adenocarcinoma in mice following developmental treatment with estrogens: A model for hormonal carcinogenesis. Cancer Res 1990; 50: 7677-7681.

36. Li S, Washburn KA, Moore R, Uno T, Teng C, Newbold RR, McLachlan JA, and Negishi M. Developmental exposure to diethylstilbestrol elicits demethylation of the oestrogen responsive lactoferrin gene in the mouse uterus. Cancer Res 1997; 57: 4356-4359.

37. Carthew R, Edwards RE, Nolan BM, Martin EA, Heydon RT, White IN, and Tucker MJ. Tamoxifen induces endometrial and vaginal cancer in rats in the absence of endometrial hyperplasia. Carcinogenesis 2000; 21: 793-797.

38. Klave G, Heuch I, and Ursin G. Reproductive factors and risk of cancer of the uterine corpus: a prospective study. Cancer Res 1998; 48: 6217-6221.

39. Noumoff JS and Faruqi S. Endometrial adenocarcinoma. Microsc Res Tech 1993; 25: 246-254.

40. Maekawa A, Onodera H, Tanigawa H, Furuta K, Kanno J, Matsuoka C, Ogiu T, and Hayashi Y. Spontaneous neoplastic and non-neoplastic lesions in aging Donryu rats. Jpn J Cancer Res (Gann) 1986; 77: 882-890.

41. Maekawa A, Takahashi M, Ando J, and Yoshida M. Uterine carcinogenesis by chemicals/hormones in rodents. J Toxicol Pathol 1999; 12: 1-11.

42. Wood GP and Toronow RC. Endometrial adenocarcinoma and the polycystic ovary syndrome. Am J Obstet Gynecol 1976; 124: 140-142.

43. Nagaoka T, Onodera H, Matsushima Y, Todate A, Shibutani M, Ogasawara H, and Maekawa A. Spontaneous uterine adenocarcinomas in aged rats and their relation to endocrine imbalance. J Cancer Res Clin Oncol 1990; 116: 623-628.

44. Nagaoka T, Takegawa K, and Maekawa A. The relationship between endocrine imbalance and alteration of rat vaginal epithelium. J Toxicol Pathol 2002; 15: 103-109.

45. Takahashi $\mathrm{O}$ and Oishi S. Disposition of orally administered 2,2-bis(4-hydroxyphenyl)propane (bisphenol A) in pregnant rats and the placental transfer to fetuses. Environ Health Perspect 2000; 108: 931-935. 